\title{
I-Gel and LMA classic in the hands of novice: A comparative study
}

\author{
Ishita Bhattacharjee ${ }^{1}$, Susanta Sarkar², Chiranjib Bhattacharyya ${ }^{3}$, Debojyoti Das ${ }^{4}$, \\ Mohanchandra Mandal ${ }^{5}$ \\ ${ }^{1}$ Post Graduate Trainee, Department of Anaesthesiology, Nil Ratan Sircar Medical College and Hospital, Kolkata, West \\ Bengal, India, ${ }^{2}$ Associate Professor, Department of Anaesthesiology, North Bengal Medical College, Sushrutanagar, \\ Siliguri, West Bengal, India, ${ }^{3}$ Associate Professor, ${ }^{4}$ Tutor, ${ }^{5}$ Professor, Department of Anaesthesiology, Institute of Post \\ Graduate Medical Education and Research/S.S.K.M. Hospital, Kolkata, West Bengal, India
}

Background: Supraglottic airway devices (SADs) such as LMA classic (cLMA), I-Gel, etc. are indispensable tool for the anaesthesiologists experienced in airway management. But studies evaluating the performance of these devices in the hands of unskilled personnel are scarce. Aims and Objective: To determine the procedure time and the proportion of patients having successful placement of I-gel and LMA classic by first-year Post Graduate Trainees (PGTs) of Anaesthesiology who tried insertion of those devices after a short training in mannequins without any hands-on training regarding placement of the devices in human. Materials and Methods: After getting Institute's Ethics Committee's approval for this interventional study, forty adult patients, posted for short surgical or gynaecological surgery, were randomly allocated in to two groups to have placement of either I-Gel (group ' $I$ ', $n=20$ ) or cLMA (group ' $C^{\prime}, n=20$ ) by first-year PGTs. The procedure time (Primary outcome) i.e. the time taken for successful placement of either device was determined and compared. A standard technique of anaesthesia was followed in every patient. Any adverse event such as sore throat, odynophagia, blood stain on the device, etc. was also recorded. Results: All patients were comparable with respect to demographic data and Mallampati scores. The mean procedure time (seconds) was considerably lower in I-Gel group compared with cLMA (63.3 \pm 57.2 versus $163.0 \pm 158.3$, respectively, $P$ value $<0.001)$. The incidence of successful placement at first attempt was significantly higher for I-Gel group. The incidence of adverse events was comparable. Conclusion: Procedure time for I-Gel insertion is significantly shorter than with LMA Classic along with a higher success rate with first attempt for the former. I-Gel may be a better alternative as airway device for the unskilled anaesthesiologist.
Access this article online

\section{Website:}

http://nepjol.info/index.php/AJMS

DOI: 10.3126/ajms.v12i9.37384

E-ISSN: 2091-0576

P-ISSN: 2467-9100

Copyright (c) 2021 Asian Journal of Medical Sciences

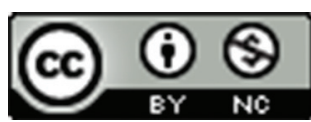

This work is licensed under a Creative Commons Attribution-NonCommercial 4.0 International License.

Key words: Adult; Anesthesiology; Airway Management; Critical Care; Humans; Intubation, Intratracheal; Outcome Assessment, Health Care; Manikins; Students

\section{INTRODUCTION}

Nowadays, the supraglottic airway devices (SADs) are widely used as an intermediate device between facemask and endotracheal tube for administration of general anaesthesia in short surgical procedures. The second generation SADs has achieved a solid and proven place as rescue device for managing difficult airways ${ }^{1,2}$ and as conduit ${ }^{3,4}$ to aid endotracheal intubation. These are also frequently used as resuscitation device to secure the airway especially in the out-of-hospital emergencies. Availability of experienced anaesthesiologist or and skilled airway manager cannot be ensured every time at all such fields for securing and maintaining airway by intubation. The doctors and paramedics working outside the discipline of anaesthesia, critical care, trauma care and emergency medicine often face difficulties to acquire the intubation skill and subsequently to maintain that. About $25 \%$ of endotracheal tubes placed by paramedical staffs in emergency department were found to be improper. ${ }^{5} \mathrm{SADs}$ 
can be used in a safer way by novice occasional airway managers, such as medical students, unskilled nurses, allied health care professionals and physicians working outside the field of anaesthesiology. In the initial phase, the Post Graduate Trainees in anaesthesiology can also be considered as novice regarding placement of SADs.

The performance of I-Gel has been compared with the LMA Proseal ${ }^{6-8}$ or with LMA Supreme. ${ }^{9}$ Several studies have been reported comparing I-Gel and LMA classic (cLMA) in adult, ${ }^{1,10-16}$ in child $\mathrm{d}^{17-19}$ and in mixed age group ${ }^{20}$ population. Some of these studies report the comparative performance of I-Gel and cLMA in the hands of experienced or skilled anaesthesiologists. ${ }^{1,10-12,17-19}$ The performance of only I-Gel in both mannequins and anaesthetized patients was reported in a single study ${ }^{21}$ when the device was used by novice users who all were unfamiliar with the use of I-Gel, cLMA or other SADs.

In a few studies the procedure time and success rate of both I-Gel and LMA have been determined and compared during the use of these devices by novice. ${ }^{22-27}$ Some of these studies have evaluated the performance of novice users during their insertion of devices in the mannequin ${ }^{22-24}$ or in the clinical scenarios. ${ }^{25-27}$ This paucity in clinical studies evaluating the performance of I-Gel and cLMA in the hands of novice ${ }^{25-27}$ was the stimulus for designing the present study. Hence, the present study was designed to compare the procedure time (Primary outcome) during placement of I-Gel or LMA Classic in the hands of firstyear Post Graduate Trainees (PGTs) of Anaesthesiology who had no previous experience in placing these devices in humans. Other outcome measures were to determine the success rate of placement of either device within single attempt. Additionally, the incidence of adverse events with the use of either device was noted and compared.

\section{MATERIALS AND METHODS}

The present study was designed to compare the procedure time regarding the placement of I-Gel and LMA classic (cLMA) by a first-year PGT of Anaesthesiology. This interventional, single-blind study was performed in a tertiary care center, a Government Medical College. After receiving permission from the Institute's Ethics Committee, 40 patients aged 18-50 years of ASA I and II, planned for short surgical and Gynaecological procedures (surgical procedures not exceeding one hour) were recruited for this study. The patients and their family members were explained about the procedure and the associated risk and benefit, in their own language. Patients with airway status of Mallampati Grade 1 and 2 were included for the present study. The patients who had anticipated difficult intubation status during pre-anaesthetic evaluation were excluded from the present study. Similarly, the patients having an increased chance for gastric regurgitation and aspiration were also excluded. Thus, the patients with simpler airway were selected owing to our nature of study evaluating the performance of first-year residents.

For this interventional study, 40 patients were selected based on inclusion and exclusion criteria and informed consent was taken from each of them. The group allocation was performed after the induction of anaesthesia. There were 40 sealed envelopes each containing a piece of paper marked as ' $\mathrm{I}$ ' or ' $\mathrm{C}$ ' (20 papers marked as ' $\mathrm{I}$ ' and 20 as 'C'). After induction of anaesthesia an envelope was randomly picked up and opened. The alphabet displayed in the paper slip corresponded to the group allocation of the patient. The patients were thus randomly divided into two groups, Group 'I' where the patients received I-Gel and Group 'C' where the patients received cLMA. The used envelope and the paper were discarded then.

In this interventional study the procedure time for successful placement of I-Gel or cLMA was determined and compared (Primary outcome). The success rate of insertion of either device in a single attempt and the adverse events occurring in either case was also compared. Correct positioning was confirmed by bilateral chest rise, bilateral equal breath sounds, 'square-head' capnograph and peripheral arterial oxygen saturation $\left(\mathrm{SpO}_{2}\right)$ more than 95\%. The case was considered 'successful' if the device was inserted in a single or two attempts. If it could not be done within two attempts it was taken as a 'failure' and tracheal intubation was done. The procedure time was calculated as the time taken from 'picking up the device to the appearance of square-head capnograph'. The adverse events included sore throat, difficulty in swallowing (dysphagia), pain on swallowing (odynophagia) and blood on devices.

In the present study, I-Gel and cLMA were inserted in the respective groups by a first-year resident without any previous exposure to use of these airway devices. The resident placed the device under the close supervision of a skilled anaesthesiologist. All the first-year residents received formal teaching and demonstration about the procedure previously with the help of a mannequin. They individually practiced 30 insertions of the devices on mannequins. The residents were allowed to perform in the present study only after the facilitator had been satisfied with their performance on mannequins. Subsequently the residents observed seniors performing the procedure on patients. However, the residents did not have any hands-on experience on patients before the start of the study. After receiving any patient in operating room $(\mathrm{OR})$, monitor was 
attached and the baseline vitals such as blood pressure, $\mathrm{SpO}_{2}$ and ECG were recorded. Subsequently, inj. fentanyl $(2 \mathrm{microgram} / \mathrm{kg})$ and midazolam $(0.03 \mathrm{mg} / \mathrm{kg})$ were administered via intravenous (i.v.) route as premedication. The patient was induced with inj. propofol $(2 \mathrm{mg} / \mathrm{kg})$ i.v. and adequate anaesthesia was determined by no response to verbal commands. Once deep plane of anaesthesia was achieved, the I-Gel or cLMA was placed according to group assignment. Anaesthesia was maintained using nitrous oxide, oxygen and sevoflurane. Throughout the procedure the hemodynamic parameters such as heart rate, systolic and diastolic blood pressure, and $\mathrm{SpO}_{2}$ were monitored. Once the procedure was over, the device was taken out after oxygenation and proper recovery. The procedure time i.e. the time required for successful insertion of each device, the proportion of patients with successful placement within single attempt and the adverse events-- all were recorded and analyzed subsequently.

Based on previous study ${ }^{26}$ and also complying with the expert opinion, a five second difference in procedure time was considered to be clinically significant. This was the effect size. For calculation of sample size by 'comparing two means', the present researcher consulted the methods and formulas as mentioned in articles of Das $\mathrm{S}$ et al., ${ }^{28}$ and Hazra A et al..$^{29}$ Setting the power of the study at $80 \%$ and permitting a type I error at 5\% (alpha value at 0.05 ) the sample size was calculated to be 16 . Assuming a $20 \%$ dropout possibility, 20 patients were recruited in each group. Hence, a total of 40 patients were recruited for the study.

The data was decoded, tabulated and analyzed with the help of a biostatistician. The data was entered in Microsoft Excel spreadsheet and analysis was done using Statistical Package for Social Studies (SPSS) version 21.0. Categorical variables were presented in number and percentage (\%) while continuous variables were expressed as mean \pm SD and median. Normality of data was tested by KolmogorovSmirnov test. If the normality was rejected then non parametric test was used. Quantitative variables were compared using independent $\mathrm{t}$ test/Mann Whitney test (when the data sets were not distributed normally between the two groups). Qualitative variables were compared using Chi-square test/Fischer's Exact test. A $P$ value of $<0.05$ was considered statistically significant.

\section{RESULTS}

The study spanned over one year approximately, from May 2019 to March 2020. Data from all 40 patients was available for analysis (Figure 1). All data were found to have normal distribution except two quantitative variables, the body mass index $\left(\mathrm{kg} / \mathrm{m}^{2}\right)$ and procedure time (in seconds) which were found to have a non-normal distribution. Hence, Mann Whitney test (non-parametric) was used for comparison of body mass index (Table-1) and procedure time. (See later, table-3). In group I the patients have received I-Gel and in group $\mathrm{C}$ the patients have received LMA classic.

There was no significant difference between the patients of the two groups regarding the demographic parameters (age, gender, BMI and ASA status). However, the majority of the patients were females. This was because almost half of the patients were recruited from Gynecology department. The Mallampati scores were comparable between the groups and thus it can be said that the level of airway difficulty was comparable between the groups.

The variable body mass index $\left(\mathrm{kg} / \mathrm{m}^{2}\right)$ was not normally distributed. Thus, non-parametric test was used for the comparison. No significant difference was seen in body mass index $\left(\mathrm{kg} / \mathrm{m}^{2}\right)$ between I-Gel and cLMA ( $P$ value $\left.>0.05\right)$.

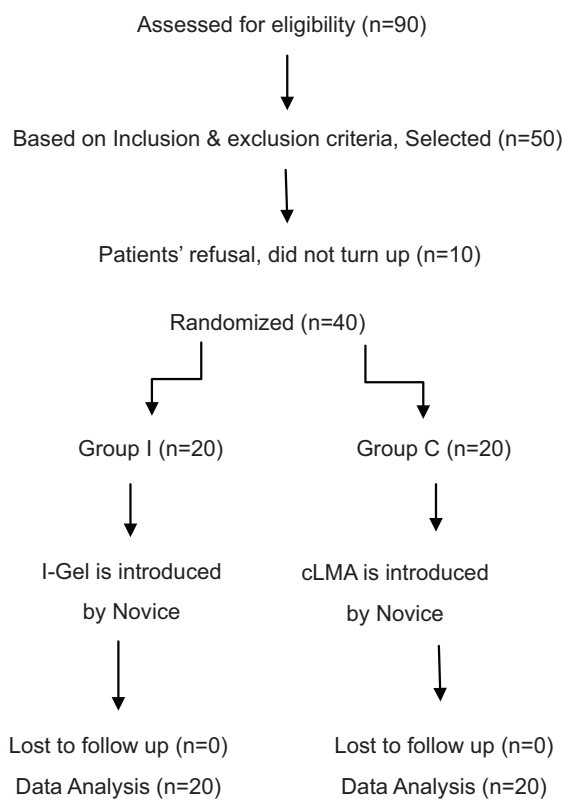

Figure 1: Flow diagram showing patient selection, randomization and lost to follow up

\begin{tabular}{lccc}
\multicolumn{4}{l}{ Table 1: Demographic data } \\
\hline Parameters & Group I $(\mathbf{n = 2 0})$ & Group C $(\mathbf{n = 2 0})$ & $\boldsymbol{P}$ value \\
\hline Age & $27.1 \pm 8.6$ & $32.8 \pm 9.8$ & 0.058 \\
Gender $^{*}(\mathrm{M} / \mathrm{F})$ & $4 / 16$ & $7 / 13$ & 0.48 \\
$\mathrm{ASA}^{\mathrm{PS}}{ }^{*}(\mathrm{I} / \mathrm{II})$ & $18 / 2$ & $17 / 3$ & 1 \\
$\mathrm{BMI}\left(\mathrm{kg} / \mathrm{m}^{2}\right)$ & $22(20-24.2)$ & $22(21-23.3)$ & 0.753 \\
{$[$ Median $(\mathrm{IQR})]$} & & & \\
\hline
\end{tabular}

The gender and ASA-PS were analysed according to *Fisher's Exact test. Age was tested with Student's $t$-test. All were found comparable. BMI is expressed as median (interquartile range). 
Mallampati score were comparable between the groups (Table-2).

As the data of procedure times was having a non-normal distribution, the Median (IQR) value of procedure time (seconds) in cLMA was found to be significantly higher as compared with that of I-Gel (Table-3).

The variable duration of insertion (seconds) was not normally distributed. Thus, non-parametric test was used for the comparison. (Table 3) Significant difference was seen in procedure time (seconds) between I-Gel and cLMA ( $P$ value $<0.05)$. Median $(\mathrm{IQR})$ value of procedure time (seconds) in cLMA was 100.5 (89117.5) which was found to be considerably higher as compared with that of I-Gel [47(43.0-57.8)]. The 'box and whisker' plot (Figure 2) depicts the distribution of duration of insertion (seconds) in the 2 groups. The middle horizontal line represents the median duration of insertion (seconds), the upper and lower bounds of the box represent the $75^{\text {th }}$ and the $25^{\text {th }}$ centile of duration of insertion (seconds) respectively, and the upper and lower extent of the whiskers represent the maximum

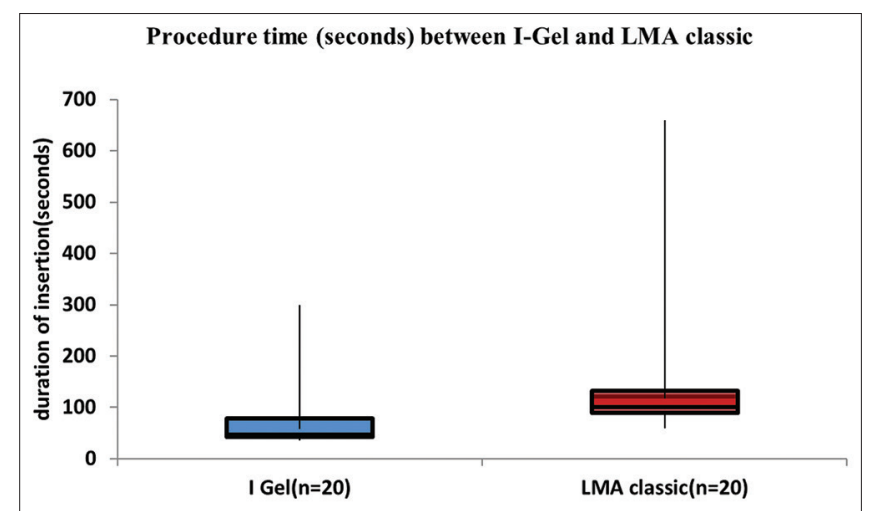

Figure 2: Box-whisker plot showing procedure times (in seconds) for placement of devices

\begin{tabular}{|c|c|c|c|c|}
\hline $\begin{array}{l}\text { Mallampati } \\
\text { score }\end{array}$ & $\begin{array}{l}\text { Group I } \\
(n=20)\end{array}$ & $\begin{array}{c}\text { Group C } \\
(n=20)\end{array}$ & Total & $P$ value \\
\hline 1 & $9(45 \%)$ & $12(60 \%)$ & $21(52.5 \%)$ & \\
\hline 2 & $11(55 \%)$ & $8(40 \%)$ & $19(47.5 \%)$ & 0.342 \\
\hline Total & $20(100 \%)$ & $20(100 \%)$ & $40(100 \%)$ & \\
\hline
\end{tabular}

Chi square test

\begin{tabular}{|c|c|c|c|}
\hline $\begin{array}{l}\text { Procedure } \\
\text { time (seconds) }\end{array}$ & $\begin{array}{l}\text { Group I } \\
(n=20)\end{array}$ & Group C $(n=20)$ & $P$ value \\
\hline Mean \pm SD & $63.3 \pm 57.2$ & $163.0 \pm 158.3$ & \\
\hline Median (IQR) & 47 (42.9-57.8) & $100.5(89-117.5)$ & $<0.0001$ \\
\hline Range & $36-300$ & $59-660$ & \\
\hline
\end{tabular}

Test performed: Mann Whitney test. IOR, interquartile range and the minimum duration of insertion (seconds) in each of the groups.

Significant difference was seen in the distribution of number of attempts between I-Gel and LMA Classic ( $P$ value $<0.05)$. Placement of the device was possible within single attempt in considerably higher number of patients in I-Gel group compared with LMA group (95\% versus 55\%, respectively). On the other hand, $2^{\text {nd }}$ attempt was required in lesser number of patients in I-Gel group compared with LMA group (5\% versus $45 \%$, respectively). It is shown in table 4 .

Apparently, lesser number of patients had adverse events in I-Gel group compared with cLMA group. Blood staining on the device was found in majority of patients $(15 \%$ in I-Gel and $25 \%$ in LMA classic). Other adverse events were dysphagia ( $5 \%$ in I-Gel versus 15\% in cLMA), odynophagia (5\% in I-Gel versus $15 \%$ in cLMA) and sore throat in very few patients ( $0 \%$ in I-Gel versus $10 \%$ of patients in cLMA group). All such adverse events were found comparable $(P$ value $>0.05)$ between the groups, when analyzed (Table 5).

\section{DISCUSSION}

This interventional study has compared the performance of one second generation SAD (I-Gel) with one first generation SAD (LMA classic) while those have been introduced in patients by novice performers. The present study finds that the procedure time for I-Gel insertion is considerably shorter than for the time for placement of cLMA in the hands of beginners. The procedure time for I-Gel was almost 2.5 times less than that of cLMA (63 seconds versus 163 seconds). This observation of the present study is in line with that of Kwak DI et al., ${ }^{24}$ where shorter procedure times were required using I-Gel compare with cLMA in mannequins with normal airway as well as difficult airway settings while the insertions were performed by novice i.e. with no prior experience in using SADs (Table 6). In the present study, insertion of cLMA required second attempts in many patients and thus further inflated the procedure time in the LMA group. Procedure time for I-Gel was also found to be almost a half to that of cLMA in several other studies (Table 6). For instance,

\begin{tabular}{|c|c|c|c|c|}
\hline $\begin{array}{l}\text { Number of } \\
\text { attempts }\end{array}$ & $\begin{array}{l}\text { Group I } \\
(n=20)\end{array}$ & $\begin{array}{c}\text { Group C } \\
(n=20)\end{array}$ & Total & $P$ value \\
\hline 1 & $19(95 \%)$ & $11(55 \%)$ & $30(75 \%)$ & \\
\hline 2 & $1(5 \%)$ & $9(45 \%)$ & $10(25 \%)$ & 0.008 \\
\hline Total & $20(100 \%)$ & $20(100 \%)$ & $40(100 \%)$ & \\
\hline
\end{tabular}


the procedure time was found to be approximately $16 \mathrm{sec}$ for I-Gel and $26 \mathrm{sec}$ for cLMA. ${ }^{10,26}$ Shorter procedure times for I-Gel insertion were also found in comparison with cLMA in many other studies. ${ }^{11-14,16,27}$

During evaluation of the performance of I-Gel in mannequins and anaesthetized patients it was observed that

\begin{tabular}{lccc}
\multicolumn{4}{l}{ Table 5: Adverse events } \\
$\begin{array}{lccc}\text { Adverse } \\
\text { events }\end{array}$ & Group I (n=20) & Group C (n=20) & P value \\
\hline $\begin{array}{l}\text { Blood on } \\
\text { device }\end{array}$ & $3(15 \%)$ & $5(25 \%)$ & 0.695 \\
$\begin{array}{l}\text { Dysphagia } \\
\text { Odynophagia }\end{array}$ & $1(5 \%)$ & $3(15 \%)$ & 0.605 \\
Sore throat & $1(5 \%)$ & $3(15 \%)$ & 0.605 \\
Analyzed with Fischer's Exact test & $2(10 \%)$ & 0.487 \\
\hline
\end{tabular}

I-Gel can be easily inserted in both mannequins and patients by an inexperienced or novice person, thereby leading to shorter procedure time and higher success rate. ${ }^{21}$ In a recent study ${ }^{30}$, the efficacy of two commonly available SADs (cLMA and I-gel) has been determined when inexperienced persons (58 paramedics and 46 medical students), after a brief training, inserted the devices in adult mannequin. The authors concluded that inexperienced persons could learn insertion of I-Gel and cLMA successfully in the mannequin after a brief training on mannequin. The firstattempt success rate and insertion of I-gel was found to be easier and faster than that of cLMA by both groups of performers and majority of participants preferred I-gel due to ease of handling. ${ }^{30}$ The performance of both the experienced and the novice physicians was assessed regarding I-Gel and cLMA insertion in mannequins in

\begin{tabular}{|c|c|c|c|c|c|c|}
\hline \multirow[t]{2}{*}{ Studies } & \multicolumn{2}{|c|}{ Procedure time (Seconds) } & \multicolumn{2}{|c|}{$\begin{array}{l}\text { Success } \\
\text { rate }(\%)\end{array}$} & \multirow[t]{2}{*}{ Performer } & \multirow[t]{2}{*}{ Nature of study } \\
\hline & I-Gel & cLMA & I-Gel & cLMA & & \\
\hline Present Study (2020) & $63.3 \pm 57.2$ & $163.0 \pm 158.3$ & 95 & 55 & & Human, Adult \\
\hline \multicolumn{7}{|c|}{ Studies with Novice performer } \\
\hline $\begin{array}{l}\text { Castle N, et al. } \\
(2010)^{22}\end{array}$ & $\begin{array}{c}12.3(11.5- \\
13.1)\end{array}$ & $\begin{array}{l}33.8(30.9- \\
36.7)\end{array}$ & - & - & Paramedic student & $\begin{array}{l}\text { Mannequin } \\
\text { study }\end{array}$ \\
\hline $\begin{array}{l}\text { Stroumpoulis K, et al. } \\
(2012)^{23}\end{array}$ & $15.2 \pm 3.4$ & $22.0 \pm 4.4$ & 90.1 & 47 & Novice & $\begin{array}{l}\text { Mannequin } \\
\text { study }\end{array}$ \\
\hline \multirow[t]{2}{*}{ Kwak DI, et al. (2013) ${ }^{24}$} & $10.0 \pm 3.7$ & $28.3 \pm 8.3$ & - & - & Novice, Normal airway & \multirow{2}{*}{$\begin{array}{l}\text { Mannequin } \\
\text { study }\end{array}$} \\
\hline & $10.3 \pm 3.0$ & $29.1 \pm 8.2$ & - & - & Novice, Difficult airway & \\
\hline $\begin{array}{l}\text { Pratheeba N, et al. } \\
(2016)^{26}\end{array}$ & $15.9 \pm 1.6$ & $26.1 \pm 5.1$ & 100 & 84 & $\begin{array}{l}\text { Final year PGTs (Trained on } \\
\text { mannequin) }\end{array}$ & Human, Adult \\
\hline Alex S, et al. (2017) ${ }^{27}$ & $13.6 \pm 3.9$ & $23.2 \pm 7.9$ & 96 & 80 & First time user & Human, Adult \\
\hline \multirow[t]{2}{*}{$\begin{array}{l}\text { Kannaujia AK, et al. } \\
(2020)^{30}\end{array}$} & $\begin{array}{l}16.8 \pm 9.1 \\
15(10-18)\end{array}$ & $\begin{array}{l}25.5 \pm 19.4 \\
15(15-26)\end{array}$ & 69 & 53 & Paramedics & \multirow[t]{2}{*}{$\begin{array}{l}\text { Mannequin } \\
\text { study }\end{array}$} \\
\hline & $\begin{array}{l}13.1 \pm 6.8 \\
10(9-15)\end{array}$ & $\begin{array}{l}19.2 \pm 10.1 \\
15(14-20)\end{array}$ & 74 & 70 & Medical students & \\
\hline \multicolumn{7}{|c|}{ Studies with Experienced performer } \\
\hline Singh J. et al. (2012) ${ }^{1}$ & 19.3 & 23.5 & 91.7 & 79.2 & $\begin{array}{l}\text { Experienced (cLMA>1000 and } \\
\text { I-Gel }>20)\end{array}$ & Human, Adult \\
\hline $\begin{array}{l}\text { Stroumpoulis K, et al. } \\
\text { (2012) } 23\end{array}$ & $11.3 \pm 5.6$ & $13.7 \pm 6.6$ & 90 & 84 & Experienced (>20 insertions) & $\begin{array}{l}\text { Mannequin } \\
\text { study }\end{array}$ \\
\hline $\begin{array}{l}\text { Helmy AM, et al. } \\
(2012)^{10}\end{array}$ & $15.6 \pm 4.9$ & $26.2 \pm 17.7$ & 90 & 80 & 'Senior Anaesthesiologist' & Human, Adult \\
\hline Lee JR, et al. (2012) ${ }^{17}$ & $\begin{array}{c}17(13.8-20) \\
{[10-40]}\end{array}$ & $\begin{array}{c}21(17.5-25) \\
{[15-70]}\end{array}$ & 96 & 92 & $\begin{array}{l}\text { Experienced (I-Gel>20; } \\
\text { cLMA >200 insertions) }\end{array}$ & Human, Child \\
\hline Kim MS, et al. (2014) ${ }^{18}$ & $\begin{array}{c}15(13-16) \\
{[9-22]}\end{array}$ & $\begin{array}{c}17(12-18) \\
{[9-69]}\end{array}$ & 100 & 84 & $\begin{array}{l}\text { Experienced (> } 100 \text { uses, each } \\
\text { device) }\end{array}$ & Human, Child \\
\hline Gupta P, et al. (2015) ${ }^{13}$ & $29.3 \pm 6.9$ & $36.7 \pm 7.3$ & 87.5 & 77.5 & NA & Human, Adult \\
\hline Ari DE, et al. (2015) ${ }^{14}$ & $21 \pm 4.2$ & $30.4 \pm 12.2$ & 88 & 88 & 'Anaesthesiologist' & Human, Adult \\
\hline Polat R, et al. (2015) ${ }^{11}$ & $11.6 \pm 2.4$ & $13.1 \pm 1.8$ & 89.8 & 89.8 & $\begin{array}{l}\text { Experienced. Both devices } \\
\text { (>200 uses) }\end{array}$ & Human, Adult \\
\hline Rao GS.et al. (2016) ${ }^{15}$ & $17.3 \pm 2.9$ & $24.9 \pm 4.8$ & 98 & 90 & NA & Human, Adult \\
\hline $\begin{array}{l}\text { Engineer SR, et al. } \\
(2016)^{20}\end{array}$ & $53.1 \pm 6.0$ & $57.8 \pm 9.8$ & 88 & 64 & NA & $\begin{array}{l}\text { Human, 5-60 } \\
\text { years }\end{array}$ \\
\hline Sivasamy G (2018) ${ }^{16}$ & $9.7 \pm 1.0$ & $17.2 \pm 2.0$ & 95 & 92 & NA & Human, Adult \\
\hline Arora V, et al. $(2018)^{12}$ & $5(5-6)$ & $23(11-27)$ & 92.5 & 80 & Skilled & Human, Adult \\
\hline $\begin{array}{l}\text { ElGohary MM, et al. } \\
(2018)^{19}\end{array}$ & $78 \pm 39.6$ & $153 \pm 63$ & 80 & 40 & NA & Human, Child \\
\hline
\end{tabular}


a single study where first-pass success rate for I-Gel was found to be high among the novice doctors, equal to those achieved by the experienced group. ${ }^{23}$ In another study ${ }^{24}$ the researchers found that easier and quicker placement by novice performers (nurses and interns) was possible with I-Gel in comparison with cLMA in both normal and difficult airway conditioned mannequins. It was also observed in that study ${ }^{24}$ that the I-gel had a higher positive response for attitude and preference.

In a clinical study ${ }^{25}$ fifty doctors and paramedical staffs were divided into two groups- skilled (more than 30 insertions of SADs) or novice on the basis of their experience, and then were timed to insert the two SADs, I-Gel and LMA. The insertion of I-Gel was found to be $67 \%$ faster than the LMA in the hands ofnovice. ${ }^{25}$ However, the procedure times of I-Gel insertion by skilled and novice groups were comparable in that study. ${ }^{25}$ In other words, novice can perform as good as a skilled person if the SAD is the I-Gel, and not the LMA.

In the present study the post graduate trainees who had no hand-on experience in placement of SADs in human have been designated as novice. What constitutes true 'experience' in handling the SADs has not been accurately standardized; different researchers have used their own criteria. ${ }^{1,10-12,17,18,23,25}$ It was mentioned in the literature with quite variation, to mention a few, device insertions on more than 20 occasions, ${ }^{23}$ insertion of each device on more than 30 occasions, ${ }^{25}$ minimum 100 insertions of each device, ${ }^{18}$ insertions of both devices on more than 200 occasions, ${ }^{11}$ insertion of I-Gel on more than 20 and cLMA on more than 200 occasions, ${ }^{17}$ placement of cLMA on more than 1000 and I-Gel on more than 20 occasions, ${ }^{1}$ and nonspecific mention of 'senior anaesthesiologists ${ }^{10}$ or 'skilled'12 only.

While comparing with other studies in the related field, the present study also shows an inflation of mean values of procedure times in both the groups (Table 3). The higher values of procedure times in both the groups in the present study may be attributed to the following facts. According to the study design, the placement of the airway devices was done by the first-year PGTs with no prior hands-on experience of placement of the devices in human subjects. This probably has inflated the procedure time unnecessarily. In the present study, the high values of standard deviation in both the groups indicate that there was a high inter-personal variation of procedure time which should get shortened a bit with improvement of performance by training.

The definition of 'procedure time' (time needed for successful insertion) varies from studies to studies and that may also explain difference in the results of various studies. ${ }^{17,31}$ For example in one study the procedure time was defined in a different way such as from the 'moment of face mask removal up to the first capnograph upstroke ${ }^{\text {17 }}$ while in the present study the procedure time was defined as the time from 'picking the device to the appearance of square waves of $\mathrm{EtCO}_{2}$ '. Here, although the end point is same, the start points differ for the calculation of procedure time.

The present study finds a $95 \%$ success rate with first attempt during use of I-Gel while it was 55\% with first attempt during use of cLMA, the difference being statistically significant (Table 3). In the second attempt another 5\% success was achieved with I-Gel and another $45 \%$ success was achieved with the use of cLMA. Thus, considering the $2^{\text {nd }}$ attempt, there was no failure in proper placement of both the devices. Pratheeba N et al., ${ }^{26}$ found 100\% success rate for proper placement of I-Gel in the first attempt while it was $84 \%$ for cLMA in the first attempt and further 16\% in the second attempt. A considerably higher success rate in the first attempt was observed with the use of I-Gel in comparison with cLMA in many other studies $^{10,12,27}$ (Table 3). However, there are other studies ${ }^{11,14}$ reporting high success rate for each of the devices without considerable differences between them (Table 3).

The shorter procedure time and higher success rate of I-Gel in the first attempt in comparison with cLMA in the present study may be due to technical and ergonomic reason such as the absence of cuff, less flexible stem (robust conducting channel), ${ }^{11}$ etc., which makes its insertion easier and there is no need for cuff inflation. The mask shape of the cLMA resembles a wedge-shaped doughnut in overall design. Their inflatable cuffs provide airway seal but can affect their insertion and position. The leading edge of deflated mask of LMA can catch the epiglottis edge and cause it to bend downwards or impede proper placement under the tongue. ${ }^{32-34}$ The mask of I-Gel is uncuffed, thereby leads to easier insertion, minimal risk of tissue compression, and offers a stability of position as there is no issue of change in position owing to cuff inflation. ${ }^{11,33}$

In the present study, the post-procedure hemodynamic parameters were found comparable in the intra- and postoperative period in both the groups.

In the present study, the adverse events such as sore throat, dysphagia, odynophagia and blood staining on the devices were higher in cLMA than I-Gel. However, on analysis, the difference was not statistically significant. Comparable adverse events between the uses of these two devices were also reported in some recent study. ${ }^{14}$ The adverse events such as cough, sore throat, dysphagia/dysphonia and blood 
stain on device were reported to be lower with the use of I-Gel compared with cLMA in many other studies. ${ }^{12,13,19,20,27}$

The study has a few limitations. Here, a second-generation SAD (I-gel) is compared with a first-generation SAD (cLMA). It was carried out in elective cases with people having Mallampatti score I and II, without any airway difficulty. Hence, the trend of procedure time and success rate of I-Gel and LMA Classic as determined in the present study may not be totally applicable in emergency settings or patients with difficult airway. The leak pressure was not measured in the present study. The fiberoptic confirmation of proper placement of airway devices was not done. The study setting was also set in comparatively shorter duration surgeries and avoided surgical areas like airway, neurosurgery, pediatric surgery etc. Hence, the inference drawn about the performance of such airway devices may not be generalized.

To summarize, the present study found that procedure time was considerably shorter (2.5 times) with the use of I-Gel. The present study also found a 95\% success rate for I-Gel which was considerably higher than LMA Classic. The adverse events were found apparently higher in LMA Classic, though it was not statistically significant.

\section{CONCLUSION}

To conclude, I-Gel is a better alternative to LMA Classic in the hands of novice residents for securing the airway in terms of shorter procedure time as well as higher success rate in the first attempt. The changes in hemodynamic parameters in the post-procedure period are comparable between the devices. The adverse events related to placement of both the devices are also comparable. Thus, I-Gel appears to be a better alternative to LMA Classic as an airway management tool for the beginners.

\section{REFERENCES}

1. Singh J, Yadav MK, Marahatta SB and Shrestha BL. Randomized crossover comparison of the laryngeal mask airway classic with i-gel laryngeal mask airway in the management of difficult airway in post burn neck contracture patients. Indian J Anaesth.2012;56:348-352. https://doi.org/10.4103/00195049.100815

2. Wong DT, Yang JJ and Jagannathan N. Brief review: The LMA Supreme ${ }^{\mathrm{TM}}$ supraglottic airway. Can J Anaesth. 2012;59(5):483-493.

https://doi.org/10.1007/s12630-012-9673-0 PMid:22318376

3. Bielski A, Smereka J, Madziala M, Golik D and Szarpak L. Comparison of blind intubation with different supraglottic airway devices by inexperienced physicians in several airway scenarios: a manikin study. Eur J Pediatr. 2019;178(6):871-882. https://doi.org/10.1007/s00431-019-03345-4

4. Dhimar AA, Sangada BR, Upadhyay MR and Patel SH. I-Gel versus laryngeal mask airway (LMA) classic as a conduit for tracheal intubation using ventilating bougie. J Anaesthesiol Clin Pharmacol. 2017;33(4):467-472. 10.4103/joacp. JOACP_113_16.

5. Katz SH and Falk JL. Misplaced tracheal tubes by paramedics in an urban emergency medical services system. Ann Emerg Med. 2001; 37:32-37.

https://doi.org/10.1067/mem.2001.112098

6. Chauhan G, Nayar P, Seth A, Gupta K, Panwar M and Agrawal N. Comparison of clinical performance of the I-gel with LMA proseal. J Anaesthesiol Clin Pharmacol. 2013;29(1):56-60. https://doi.org/10.4103/0970-9185.105798

7. Saran S, Mishra SK, Badhe AS, Vasudevan A, Elakkumanan LB and Mishra G. Comparison of i-gel supraglottic airway and LMA ProSeal $^{\mathrm{TM}}$ in pediatric patients under controlled ventilation. J Anaesthesiol Clin Pharmacol. 2014;30(2):195-198.

https://doi.org/10.4103/0970-9185.130013

8. Jadhav PA, Dalvi NP and Tendolkar BA. I-gel versus laryngeal mask airway-Proseal: Comparison of two supraglottic airway devices in short surgical procedures. J Anaesthesiol Clin Pharmacol. 2015;31(2):221-225.

https://doi.org/10.4103/0970-9185.155153

9. Radhika KS, Sripriya R, Ravishankar M, Hemanth Kumar VR, Jaya $V$ and Parthasarathy $S$. Assessment of suitability of I-gel and laryngeal mask airway-supreme for controlled ventilation in anesthetized paralyzed patients: A prospective randomized trial. Anesth Essays Res. 2016;10(1):88-93.

https://doi.org/10.4103/0259-1162.167849

10. Helmy AM, Atef HM, El-Taher EM and Henidak AM. Comparative study between I-gel, a new supraglottic airway device, and classical laryngeal mask airway in anesthetized spontaneously ventilated patients. Saudi J Anaesth. 2010;4(3):131-136.

https://doi.org/10.4103/1658-354X.71250

11. Polat R, Aydin GB, Ergil J, Sayin M, Kokulu T and Öztürk I. Comparison of the I-gelTM and the Laryngeal Mask Airway ClassicTM in terms of clinical performance. Rev Bras Anestesiol. 2015;65(5):343-348.

https://doi.org/10.1016/j.bjan.2014.02.009

12. Arora V, Fotedar S, Khan MZ, Awasthi G, Arya AK and Singh V. A comparison between the I-gel and the LMA classic in spontaneously ventilating anaesthetized patients. J Evolution Med Dent Sci. 2018;7(08):1034-1039.

https://doi.org/10.14260/jemds/2018/236

13. Gupta P, Kumar A, Jethava DD, Kapoor S and Jethava D. A comparison of I-gel with the LMA-classic in spontaneously breathing patients. Ain-Shams J Anaesthesiol. 2015; 8:179-182. https://doi.org/10.4103/1687-7934.156672

14. Arı DE, Ar AY, Karip CŞ, Siyahkoç I, Arslan AH and Akgün FN. Comparison of I-gel with Classic Laryngeal Mask Airway Regarding the Ease of Use and Clinical Performance. Turk J Anaesthesiol Reanim. 2015;43(5):299-303.

https://doi.org/10.5152/TJAR.2015.71542

15. Rao GS, Shivani V, Pandu Naik RP and Kanuri M. Comparison of Clinical Performance of the i-Gel with Laryngeal Mask Airway (LMA) Classic-A Randomized Study. JMSCR 2016;4(2):93609370.

http://dx.doi.org/10.18535/jmscr/v4i02.44

16. Sivasamy G, Jalakandan B, Thirunavukkarasu MJ, Raghuraman MS and Shafeek AK. Evaluation of i-Gel and LMA-C Clinical Presentation in Anaesthetized Patients. Indian Journal of Anesthesia and Analgesia. 2018;5(11):1823-1828. https://doi.org/10.21088/ijaa.2349.8471.51118.8 
17. Lee JR, Kim MS, Kim JT, Byon HJ, Park YH, Kim HS, et al. A randomised trial comparing the i-gel (TM) with the LMA Classic (TM) in children. Anaesthesia. 2012;67(6):606-611. https://doi.org/10.1111/j.1365-2044.2012.07072.x

18. Kim MS, Oh JT, Min JY, Lee KH and Lee JR. A randomised comparison of the $\mathrm{i}$-gel $\mathrm{I}^{\mathrm{TM}}$ and the Laryngeal Mask Airway Classic $^{\text {TM }}$ in infants. Anaesthesia. 2014;69(4):362-367. https://doi.org/10.1111/anae.12592

19. EIGohary MM, Samuel EW and Botros JM. Comparative study between I-Gel,ProSeal,and classical laryngeal mask airways in pediatrics: a randomized controlled trial. Res Opin Anesth Intensive Care. 2019; 6:182-187.

https://doi.org/10.4103/roaic.roaic_87_17

20. Engineer SR, Jansari DB, Saxena S and Patel RD. A comparative study between i-gel and classical laryngeal mask airway in elective surgery under general anaesthesia. Int J Sci Rep. 2016; 2(9):227-232.

https://doi.org/10.18203/issn.2454-2156.IntJSciRep20163110

21. Wharton NM, Gibbison B, Gabbott DA, Haslam GM, Muchatuta N and Cook TM. I-gel insertion by novices in manikins and patients. Anaesthesia. 2008;63(9):991-995.

https://doi.org/10.1111/j.1365-2044.2008.05542.x

22. Castle N, Owen R, Hann M, Naidoo R and Reeves D. Assessment of the speed and ease of insertion of three supraglottic airway devices by paramedics: a manikin study. Emerg Med J. 2010;27(11):860-863.

https://doi.org/10.1136/emj.2009.084343

23. Stroumpoulis K, Isaia C, Bassiakou E, Pantazopoulos I, Troupis G, Mazarakis A, et al. A comparison of the i-gel and classic LMA insertion in manikins by experienced and novice physicians. Eur J Emerg Med. 2012;19(1):24-27.

https://doi.org/10.1097/MEJ.0b013e3283474ab3

24. Kwak DI, Yoo JH, No HW, Sohn JD, Kim YJ and Nah JH. Comparison between the LMA ClassicTM and new I-gelTM supraglottic airway device: a manikin study. Hong Kong J Emerg Med. 2013;20(1):25-33.

https://doi.org/10.1177/102490791302000104

25. Jindal P, Rizvi AA, Khurana G and Sharma JP. Safety and efficacy of insertion of supraglottic devices in anaesthetised patients by first time users, South Afr J Anaesthesiol Analg. 2010;16(4):23-26. https://doi.org/10.1080/22201173.2010.10872694

26. Pratheeba N, Ramya GS, Ranjan RV and Remadevi R. Comparison of $\mathrm{i}-\mathrm{gel}^{\mathrm{TM}}$ and laryngeal mask airway Classic ${ }^{\mathrm{TM}}$ in terms of ease of insertion and hemodynamic response: A randomized observational study. Anesth Essays Res. 2016;10(3):521-525.

https://doi.org/10.4103/0259-1162.180780

27. Alex S, Varghese BS, Ramadas CK and Krishnan V. Comparison of Insertion Characteristics of I-Gel and Classic LMA by First Time Users. Ann. Int Med Den Res. 2017; 3(3):AN45-AN48. https://doi.org/10.21276/aimdr.2017.3.3.AN9

28. Das S, Mitra K and Mandal M. Sample size calculation: Basic principles. Indian J Anaesth 2016;60(9):652-656.

https://doi.org/10.4103/0019-5049.190621

29. HazraAand Gogtay N. Biostatistics Series Module 5: Determining Sample Size. Indian J Dermatol 2016;61(5):496-504. https://doi.org/10.4103/0019-5154.190119

30. Kannaujia AK, Srivastava U, Singh T and Haldar R. Evaluation of I-Gel ${ }^{\mathrm{TM}}$ versus classic $\mathrm{LMA}^{\mathrm{TM}}$ for airway management by paramedics and medical students: A manikin study. Anesth Essays Res. 2020; 14:166-169.

https://doi.org/10.4103/aer.AER_37_20

31. Luthra A, Chauhan R, Jain A, Bhukal I, Mahajan S and Bala I. Comparison of two supraglottic airway devices: I-gel airway and ProSeal laryngeal mask airway following digital insertion in nonparalyzed anesthetized patients. Anesth Essays Res. 2019; 13:669-675.

https://doi.org/10.4103/aer.AER_132_19

32. Levitan RM and Kinkle WC. Initial anatomic investigations of the I-gel airway: A novel supraglottic airway without inflatable cuff. Anaesthesia. 2005;60(10):1022-1026.

https://doi.org/10.1111/j.1365-2044.2005.04258.x

33. Hernandez MR, Klock PA and Ovassapian A. Evolution of the extraglottic airway: a review of its history, applications, and practical tips for success. Anesth Analg. 2012;114(2):349-368. https://doi.org/10.1213/ANE.0b013e31823b6748

34. Solanki SL, Johnson JE and Samantaray A. Supraglottic airway devices: Placement and pharyngeal seal matters! Indian J Anaesth. 2020;64(8):649-652.

https://doi.org/10.4103/ija.IJA_938_20

\footnotetext{
Authors Contribution:

IB- Participated in the concept of study design, conduct of study, data collection, writing of first draft; SS- Helped in concept of study, subsequent designing, helped in data analysis, participated in the interpretation of result, review of literature and critically revising the first draft; CB-participated during the concept of study design, time to time follow up regarding progress of study, helped in statistical analysis and logical conclusion, participated in review of literature, contributed with critical revision of first draft; DD- Helped in concept of study, statistical analysis of data and logical conclusion of analyzed result, helped IB during first draft and subsequent revision of first draft; MM- Participated in the concept of the study, daily guidance regarding the conduct of the study, helped in data analysis and to arrive at logical conclusion, review of literature, extensive revision of the first draft

Work attributed to:

Nil Ratan Sircar Medical College and Hospital, Kolkata, West Bengal, India.

Orcid ID:

Dr. Ishita Bhattacharjee - (1) https://orcid.org/0000-0002-1158-1133

Dr. Susanta Sarkar - (D) https://orcid.org/0000-0002-2298-7366

Dr. Chiranjib Bhattacharyya - (1) https://orcid.org/0000-0003-2879-4933

Dr. Debojyoti Das - ittps://orcid.org/0000-0002-3406-151X

Prof. Dr. Mohanchandra Mandal - (i) https://orcid.org/0000-0003-4183-993X

Source of Support: Nil, Conflict of Interest: None declared.
} 